\section{UAB}

Universitat Autònoma de Barcelona

\section{Dipòsit digital \\ de documents de la UAB}

This is the accepted version of the article:

Martí Olivé, Joel; Bolíbar, Mireia; Lozares Colina, Carlos. «Network cohesion and social support». Social Networks, Vol. 48 (2017), p. 192-201. DOI 10.1016/j.socnet.2016.08.006

This version is avaible at https://ddd.uab.cat/record/203906

under the terms of the (cc) BY-NC-ND license 


\title{
Network cohesion and social support
}

\author{
Joel Martí \\ Centre d'Estudis Sociològics sobre la Vida Quotidiana i el Treball (QUIT) \\ Institut d'Estudis del Treball (IET) \\ Universitat Autònoma de Barcelona \\ Joel.Marti@uab.cat \\ Mireia Bolíbar \\ Institute for Sociology \\ University of Bremen \\ Carlos Lozares \\ Centre d'Estudis Sociològics sobre la Vida Quotidiana i el Treball (QUIT) \\ Institut d'Estudis del Treball (IET) \\ Universitat Autònoma de Barcelona
}

The final version of this paper has been published in Social Networks by Elsevier:

Martí, J., Bolíbar, M., Lozares, C. (2017). Network cohesion and social support. Social Networks, 48, 192-201. https://doi.org/10.1016/j.socnet.2016.08.006 


\title{
Network cohesion and social support
}

\begin{abstract}
This article analyses the effects of personal network cohesion on different types of social support using two dimensions of cohesion: network closure (defined as a tightly knit set of actors around the ego) and cliquishness (defined as the extent to which an actor is connected with a number of cohesive sub-sets of alters). Data were obtained from a personal networks' survey conducted in Catalonia (Spain), which was completed by 441 adults and gathered information about exchange of social support in networks made of 30 alters. A multilevel analysis disentangles the effects on support of these two structural dimensions at the network-level from compositional effects at the network and tie-level. The results show that network closure does not play a relevant role in support once confounders at the network and tie levels are controlled for. However, cliquishness has a significant association with labor-related support and housing support, net of statistical controls. Implications of these results in network research are discussed.
\end{abstract}

\section{Keywords}

Social support; Personal networks; Network effects; Cohesion; Density; Cliques 


\section{Network cohesion and social support}

\section{Introduction}

A sizable research literature about social support has developed over the past few decades. Despite the diversity of extant approaches, substantial advances in its conceptualization can be highlighted. First, social support is considered to be the relationship-based practice of an assisting nature (Song et al., 2011). Second, social support has been defined as a multi-dimensional phenomenon: the seminal work of House (1981) distinguished between emotional, instrumental, informational and appraisal support. Lin et al. (1986: 18) distinguished between instrumental and expressive support on the one hand and actual and perceived support on the other. Other scholars have addressed social support in light of the contexts in which it occurs, such as everyday situations as opposed to emergencies (Wellman and Wortley, 1990). Third, by limiting the concept of social support to the flow of specific content across ties, research has distinguished it from its relational preconditions (availability of ties) and from its social outcomes, such as health, well-being or status attainment (Berkman and Glass, 2000; Song et al., 2011; Walker et al., 1993; Wellman and Gulia, 1999).

In this paper, we assume the relational and multidimensional understanding of this phenomenon: the role of the network structure, and particularly cohesion, in fostering support (Haines et al., 2002; Walker et al., 1993; Wellman and Frank, 2001; Wellman and Gulia, 1999; Wellman and Wortley, 1990). We particularly focus on two dimensions of personal network cohesion: overall network closure (defined as tightly knit personal networks) and cliquishness (defined as the extent to which an actor is in contact with a number of cohesive sets of actors). The goals of the article are (1) to discuss and explore the concept of network cohesion and the distinct dimensions in 
which it is expressed in personal network structures, and (2) to analyse the extent to which these two dimensions are related to different types of social support, i.e., the exchange of information or assistance for solving problems related to: (a) personal concerns, (b) health, (c) labor, and (d) housing. Following previous suggestions regarding the need of expanding the range of network concepts and measures to improve understanding of the determinants of social support (Haines et al., 2002: 286), we specifically demonstrate that the overall network closure does not sufficiently account for the structural effects of network cohesion on social support. The local subgroup structure within personal networks needs to be taken into account, because the extent to which an actor is connected to multiple cohesive sub-sets of alters plays a significant role on certain types of support.

The article is divided in five parts. In the following section we review the literature on the factors that lead to the exchange of social support. Section 3 focuses more specifically on the structural dimensions of network cohesion and their association with nature of social support and focus on a fourth advancement in the social support; we present our theoretical approach and the specific objectives in this section of the paper. Then we present the data and measures used for the analysis. Section 5 addresses, in the first place, a factor analysis of structural network measures aimed at identifying two distinct dimensions of network cohesion and, in the second place, multilevel regression models are used to analyze their associations with different types of support. The paper closes with a discussion of the structural effects of networks and their implications on network research. 


\section{Factors that lead to social support: from actors and ties to a network-level approach.}

Research that analyses how personal networks are related to social support has commonly dealt with three types of explanatory factors: actor properties, tie properties and network properties (Wellman and Frank, 2001).

The first group of explanations is related to the characteristics of the givers and receivers of support. For instance, research has found that women are more likely than men to provide emotional support (Hogan et al., 1993; Plickert et al., 2007; Vaux, 1985; Wellman and Wortley, 1990) and that age is also associated with a variety of types of support (Haines et al., 1996; Plickert et al., 2007). Regarding country of origin, de Miguel and Tranmer (2010) found that immigrants in Spain were more likely to exchange material support with Spaniards, whereas accommodation and informational support were more likely to be exchanged with other immigrants. The extent to which actors have access to social resources also explains their ability to exchange support; for example, urban residents and employed individuals are more capable of providing information about jobs than rural residents and individuals outside of the labor market (Trimble, 2012). However, this rationale may not be applicable to socioeconomic status: while people with a high status may have more resources to share, they may have less of a need to rely on networks because of their better access to formal sources of support (de Miguel and Tranmer, 2010). Thus, research results regarding the effects of socioeconomic status on social support are mixed (Plickert et al., 2007; Wellman and Wortley, 1990).

The second group of explanations comprises the characteristics of ties. At this level of analysis, researchers have primarily focused on three elements: the accessibility 
of the contact, the strength of the relationship and the similarities between the ego and alter. First, the accessibility of ties may increase mutual awareness of needs and facilitate the delivery of aid (Plickert et al., 2007). In this regard, Wellman and Frank (2001) found that a combined measure of accessibility (frequency of contact and physical proximity) was associated with support. However, other authors have argued that some types of support, such as emotional or financial support, are relatively less dependent on physical contact and that some groups, such as immigrants, primarily rely on transnational social ties for these types of support (Herz, 2015; Plickert et al., 2007). The relevance of tie strength in the provision of social support was addressed by Homans (1961) and has been largely developed by network researchers who demonstrated that strong ties are particularly related to expressive support, instrumental support and emergency support (Herz, 2015; Wellman and Frank, 2001; Wellman and Wortley, 1990). Finally, the homophily principle (McPherson et al., 2001) suggests that individuals who are similar to each other tend to have similar needs and interests and relatively high empathetic understandings, which may facilitate the exchange of social support (Wellman and Wotley, 1990). However, and inversely to the homophily principle, relationships across social categories may provide complementary resources and access to diverse sources of support (Wellman and Gulia, 1999; Wellman and Wotley, 1990).

A third group of explanations focuses on the network-level. This approach assumes that the presence of third actors affects the nature of dyadic relations and, thus, the social support one can access or provide is affected not only by the properties of single actors and ties but also by a network effect. However, research that analyses network effects on support often does so by measuring support as a network-level variable, e.g., the number of ties providing support (Wellman and Gulia, 1999) or the 
perceived availability of support in the network (Ashida and Heaney, 2008; Seeman and Berkman, 1988). This approach does not allow to disentangle network-level effects from tie-level effects. Only when a multilevel framework is adopted the analysis can remain at the tie-level while taking also into account the properties of the network. This multilevel approach was adopted by Wellman and Frank (2001) and, more recently, by Herz (2015).

At the network level, researchers have focused on the composition and structure of the networks in which support is being exchanged. For network composition, aggregate measures at the level of the alter or at the level of the tie (e.g., the proportion of females or the mean frequency of contact) and measures of specific network characteristics can be analyzed, such as network size and network diversity. With respect to aggregate measures of tie and alter properties, Wellman and Frank (2001) showed that the probability of an extant tie providing support is both a product of certain properties of the tie and a product of the aggregate measures of these properties for the overall network: for instance, while accessible alters (with whom there is a frequent contact or are living nearby) provided more support, if the mean accessibility of the network is accounted for, the probability of each alter providing support is even higher. Regarding network size, previous research analyzing support as a network-level variable has demonstrated that a higher number of members in a network increases access to emotional support (Seeman and Berkman, 1988; Wellman and Gulia, 1999); nevertheless, using a multilevel approach Wellman and Frank (2001) showed that egos who have a smaller network of intimates are more likely to receive support from each of them.

Finally, network diversity concerns intra-network variation, and the reasoning behind relating it to social support at the network level is derived from the 
similarity/dissimilarity debate (see Wellman and Wortley, 1990). This debate argues that contacts within or without social groups constitute two different forms of social capital (Adler and Kwon, 2000; Putnam, 1997, 2000). As previously mentioned, while ties with those who are different may provide access to various and more interdependent sources of support, a network with relatively more similar ties may foster supportiveness because the network's members have shared interests and needs (Putnam, 2000; McPherson et al., 2001). Wellman and Gulia (1999) used a composite index of network diversity that included marital status, employment status, religious affiliation, ethnicity, network members' ages, educational similarity between the network members and the respondents, and socioeconomic status. They found a positive and significant effect of diversity on providing all types of social support (companionship, minor services, major services, and emotional support). ${ }^{1}$ Similarly, Lin and Ao (2008, as cited in Song et al., 2011: 120) found that employees receive more informational support when their personal networks have a higher range (i.e., the difference between the highest and the lowest status positions in the network), extensity (i.e., the number of distinct positions) and upper reachability (highest accessed positions). Regarding the structural dimension of the network, the attention is focused on the relationships among alters and how these relationships affect the provision of social support. The next section addresses this issue in further detail through the concept of network cohesion.

1 However, as Campbell et al. (1986) and Huang and Tausig (1990) pointed out, network diversity is a multidimensional concept, and different dimensions can be associated with access to different social resources. Moreover, beyond diversity, access to high status alters is another important aspect in resource access. 


\section{Cohesion as a structural network property fostering support.}

\subsection{Social cohesion: concept and dimensions}

In this section, we discuss two distinct aspects of a network's structure that may express social cohesion: network closure and cliquishness.

Social cohesion is a concept that has been used with multiple meanings in social sciences (see Bernard, 1999; Chan et al., 2006; Friedkin, 2004; Levi, 1998). It can be considered a resource of a group or society that affects both individual actors and the overall group (Lin, 2001). Cohesion has been associated with trust, identity, reciprocity, commitment and shared values in the political, economic and cultural fields (Baker and Obstfeld, 1999; Forrest and Kearns, 2001; Jenson, 1998; Klein, 2013).

In the field of social network analysis, cohesion has also been associated with bonding relationships (Putnam, 2000), as ties with similar actors tend to be transitive (Louch, 2000; Marsden, 1987).

However, the problem with this approach is that it does not allow to distinguish the structural dimension from the properties of social ties and actors. Because of the extant association among measures such as network density, homogeneity of actors and strength of ties, an analysis aimed at measuring the effects of network cohesion on social support must account for network homogeneity and tie strength to assess the net effects of the structural aspect of cohesion.

From a structural standpoint, cohesion refers to the general level of connectedness, i.e., the presence or extent of ties among actors (therefore related to the degree of the nodes), and the general "inclusiveness" (Scott, 2000) and "connectivity" (Wasserman and Faust, 1994) of a network. Density is usually the most frequently used indicator, but measures such as number of isolated nodes, the clustering of nodes in 
components and its nested structures are also involved in defining the patterns of inclusiveness and the general shape of a network (Scott, 2000).

However, we argue that understanding social cohesion as a unidimensional concept that conveys the closure of a network does not successfully account for the whole complexity of the concept. In fact, following Hanneman and Riddle (2005), two different approaches to unravelling network structures could be identified. On the one hand, a top-down approach that assesses network cohesion by looking at the overall number of connections and the general closure of the structure they form, identifying the main lines of division or cleavages that de-compose the network into separate parts. On the other hand, a bottom-up approach to the structuring of networks focuses on how micro structures "emerge" from the dynamic processes by which actors establish dyadic connections and build cohesive subgroups. These two approache sactually identify, in our view, two different aspects of network cohesion, bringing to the fore its

multidimensional nature: the former dimension, which expresses the whole overall closure of a network (Burt, 2001), is better captured by measures such as density, number of components or number of isolates. The latter, focusing on the local connectivity and mutuality within substructures and the articulation of connectedness around cohesive sub-groups within the network, is better captured by the characterization of cliques.

\subsection{Social cohesion and social support}

Closure and social support

Network researchers have argued that dense networks of alters may facilitate communication about needs, improve coordination for the effective delivery of support and increase group pressure to provide support (Wellman and Gulia, 1999; Wellman 
and Frank, 2001). Conversely, a network with high density might imply redundancy, limiting access to new ties and bridges that could be alternative sources of support (Burt, 1992, 2000; Granovetter, 1973).

Previous studies have found that density is related to some types of social support, although the results are not conclusive. Research on emergency situations demonstrated that individuals with denser networks activated their core ties for informal support to a greater extent (Hurlbert et al., 2000) and that average closeness was related to the perceived adequacy of support (Haines et al., 2002). Similarly, Haines and Hurlbert (1992) found that higher network densities increased access to emotional aid and companionship among men. Wellman and Gulia (1999), using a combined measure of network density and percentage of kin, also found some effect on emotional and material support, although it was weaker than the effects of network diversity and availability. Using multilevel analysis Herz (2015) found no significant effects of network density on receiving any type of social support at the tie level in a sample of German migrants in Great Britain.

Despite its contributions to our understanding of social support in social networks, as previously argued, this dimension of cohesion does not successfully account for the ability of the ego to be in contact with multiple relational spaces. While dense networks tend toward creating a unique group with high levels of social closure, less dense networks may enable egos to be connected with different subgroups that provide access to a variety of resources and information. The notion of cliquishness may be useful for understanding this aspect. 
Cliquishness as sub-group cohesion and social support

Although network research has studied the relevance of ties that are embedded in cliques (see Krackhardt, 1999), little research has been conducted to address the association between social support and membership in multiple cohesive subgroups. Wellman and Wortley (1990) argue that relations within subgroups may be more supportive than ego-alter dyadic relations. Moreover, potential sources of support may be increased by contact with multiple subgroups in, for example, the labor market, community organizations, or a romantic partner's kin.

Previous research has yielded mixed results for this issue. Lin et al. (1999) demonstrated that participation in community organizations is associated with instrumental support but not with expressive support. On the other hand, Wellman and Wortley (1990) found that interaction within groups was (weakly) associated with companionship (e.g., companions who discuss ideas at work or participate in organizational activities), but not with other types of support (small and large services and emotional).

This distinction between closure and cliquishness as two different dimensions of structural cohesion is represented in Fig. $1 .^{2}$ From this distinction, the analysis presented

2 Isolated alters can, of course, be sources of support, directly and indirectly (as intermediaries) because they may indirectly link egos with alters at distances $>1$ (Burt, 2000; Granovetter, 1973). However, the lowest-density personal network (i.e., composed only by ego-alter dyads) can not benefit from group dynamics fostering social support. 
in this paper addresses two objectives. First, using empirical personal network data, it aims to identify the two structural dimensions of networks that have been discussed, closure and cliquishness. In the process of this, it assesses the measures that are appropriate for explaining their variability. Specifically, the first part of the analysis identifies the extent to which network density, the number of isolates, and the number of components demonstrate an underlying factor (closure) that is not correlated with a second factor (cliquishness), operationalized as the number of cliques. The second objective is to analyze the effects of these two factors on the exchange of social support. The goal is to determine whether the effect of the network's structure, defined in a way that distinguishes the two underlying dimensions of network cohesion, persists when controlling for the effects of the properties of ego, alter, tie and network composition.

Figure 1. Closure and cliquishness in personal networks (ego excluded from view)

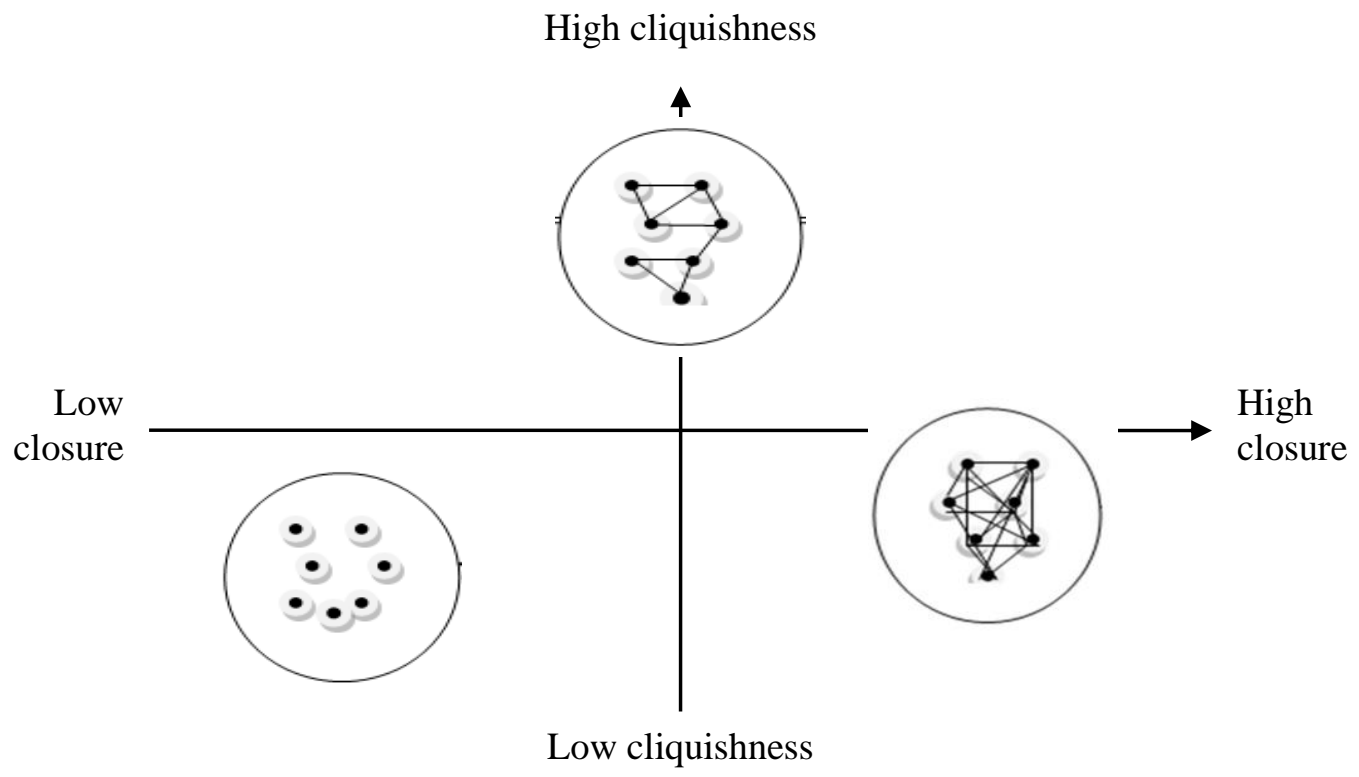




\section{Methods}

\subsection{Data}

The data used in the analysis were derived from responses to questions asked in a personal networks' survey conducted in Catalonia (Spain) in late 2009 and early 2010. The data were gathered using Egonet, which is a software program developed by Christopher McCarty and collaborators that records personal network data and computes standard compositional and structural measures. The questionnaire was completed by 441 adults over 18 years of age. Information was gathered from the respondents on: (1) the socio-demographic characteristics of the respondent, referred to herein as the "ego", (2) 30 adults with whom the respondent had had contact in the past two years by any means, referred to herein as "alters"3 (3) the relationships between the ego and alters, including their exchange of social support, and (4) the relationships

\footnotetext{
3 The alters, or contacts, were elicited by asking the respondents for the names of 30 individuals in their personal networks using McCarty's (2002) name generator method. The interviewers first asked about the individuals with whom the respondents had close contact and then extended the list to include other individuals with whom the respondents had less intimate but still frequent contact. The list was further extended to include individuals with whom the respondents were acquainted in their everyday lives (see the Appendix A for further details).
} 
between all pairs of alters. ${ }^{4}$. These data enabled an analysis in which the composition and structure of the personal networks were simultaneously taken into account.

The data collection was conducted in three Catalan cities, Barcelona, Sant Feliu de Llobregat, and Balaguer, which are the capital city of Catalonia, a medium-sized town in the Barcelona metropolitan area, and the small capital of a rural county, respectively. Within each area, a non-proportional sampling strategy was implemented that balanced quotas by sex, age, and birth country for three countries of origin (Spain, Ecuador, and Morocco $)^{5}$. Although the sample was non probabilistic, we deliberately avoided a snowball strategy in order to prevent overlapping in the observed networks.

\subsection{Measures}

The questionnaire included four binary measures of social support that measured, for every ego-alter tie, if the ego had in the past exchanged information or assistance in solving problems regarding: (a) personal concerns, (b) health, (c) labor, and (d) housing (see details in Appendix A). Although these measures were not directional (the

\footnotetext{
${ }^{4}$ Relationship between each pair of alters was measured as a non-directed tie, asking the respondents if each pair of alters knew each other, understanding by "knowing" that (a) they knew each other by their name, (b) they had had contact in the last two years by any means, and (c) they would be able to contact each other if they had to (see detail in Appendix A).

${ }^{5}$ Morocco and Ecuador are the two primary countries of origin for non-European Union immigrants to Catalonia according to Municipal Population Registers (Statistical Institute of Catalonia, 2010).
} 
questions did not include whether the alters provided information or assistance to the egos or vice versa), previous studies have underscored the bidirectional nature of social support as a reciprocal practice (Pearlin, 1985, cited in Song et al., 2011; Plickert et al., 2007; Wellman and Frank, 2001). Measures of the network structure were based on responses to questions about the relationships among the alters. Four measures were analyzed: (1) network density (among the 30 alters, excluding ego-alter ties), (2) the number of strong components, (3) the number of isolates, and (4) the number of cliques (maximal fully-connected complete sub-graphs of three or more nodes). These data were used to create two synthetic factors, described in the first part of the results section, that express the bi-dimensional nature of structural cohesion (closure and cliquishness).

Two aspects were considered regarding network composition: the size of the sub-network of close ties and aggregated measures of alter's characteristics. Because the number of alters was fixed for all of the respondents, the size of the network is a constant. However, we did consider for this variable the number of alters with an "intimate" or "very close" relationship with the ego (which represent the two upper categories on a 5-point scale). With respect to aggregated measures of alters' characteristics we used three factors extracted from a principal component analysis containing the following variables: mean age of the alters of the network, age standard deviation, proportion on kin, proportion of alters with higher education, index of qualitative variation for educational levels (considering five categories: no studies; compulsory education; secondary education; vocational training; higher education) and index of qualitative variation for occupational status (based on the following categories: employers and managers; technicians and professionals; other occupations; and not classifiable). Three components were extracted (see Appendix B for further details). 
The first one reflects the age span of the network (high factor scores stand for high age means and standard deviations) and is also related to a higher proportion of kin. The second factor shows the diversity in social status (the more the variability in educational levels and occupational status of alters, the higher the factor score). And the third factor shows the social status level of the network, being higher educated networks in the positive pole and networks with a high proportion of kin in the negative pole of the factor.

Regarding tie properties, three previously discussed elements were considered: physical accessibility (a dichotomous variable based on whether the ego and alter live in the same city or not), strength of the relationship (emotional proximity measured on a 5point scale), and similarity between the ego and alter (with three measures: same sex, same country of origin, and absolute age difference between them).

The final group of measures includes the characteristics of egos and alters. The variables included in the analysis are the following (categorical variables have been dichotomized): sex, age, country of birth (Spain or abroad), educational attainment (higher education or not), employment status (employed or not), occupational status (employers and self-employed vs. other situations), and area of residence (urban or rural).

Descriptive statistics for the study variables are shown in Table 1.

While our sample does not differ from the population with respect to age and sex distribution, the immigrant population was deliberately overrepresented in the sampling strategy because other analysis within the same research project were aimed at comparing the immigrant with the autochthonous population. The homophilic nature of personal networks, which can be observed in ego-alter ties characteristics, also leads to a relatively high percentage of alters born abroad, representing the $29 \%$ of the sample. 
Table 1. Summary statistics for study variables

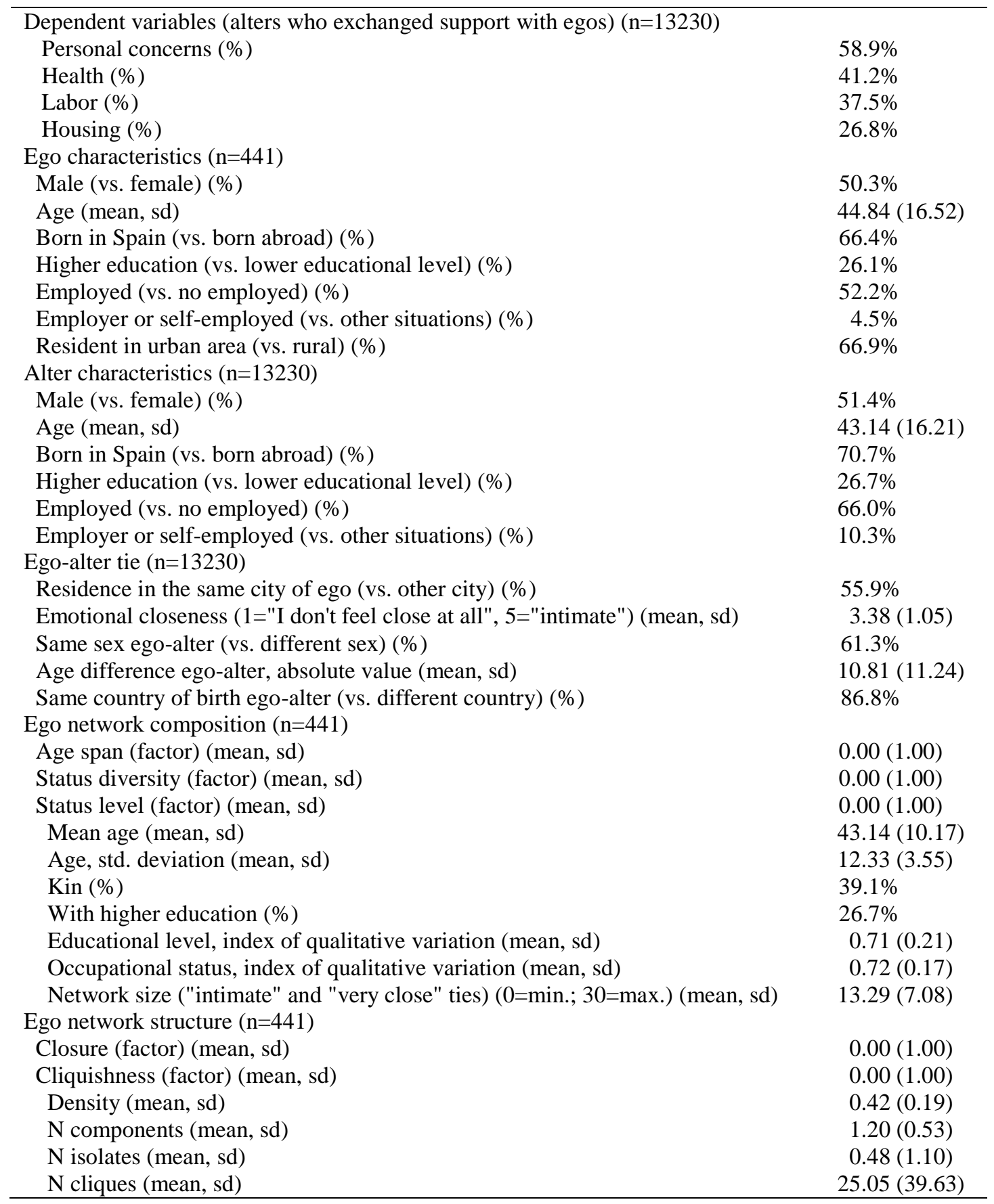

The structural and compositional properties of networks, shown in Table 1, are difficult to compare with previous large-scale personal network research due to the differences in network sizes, in the name generators and in the items identifying alter- 
alter ties used. However, densities above $40 \%$ were also found in the studies conducted in California by Fischer (1982), in France by Grossetti (2007) and in Spain by MayaJariego and Holgado (2015). McCarty (2002) found lower densities (24\%) in 45 networks with 60 alters, with higher mean values in cliques than in our sample (74.3 vs. 25.1 in our sample) and also higher in components (1.9 vs. 1.2 in our sample).

Regarding support exchange, while the majority of the 13,230 sampled alters exchanged support on personal concerns with egos, this percentage decreased to less than $27 \%$ in housing support. Again, these proportions are difficult to compare with previous research due to methodological differences.

\subsection{Analysis}

The first part of the analysis is aimed at exploring the dimensional structure of four network measures related to network cohesion. To this aim, a principal component analysis is conducted. In the second part, a multilevel analysis is used to assess the effects of the two dimensions of network structure (closure and cliquishness) on the four measures of social support: (a) personal concerns, (b) health, (c) labor, and (d) housing. Multilevel analysis (Snijders et al., 1995; Van Duijn et al., 1999) has previously been used in the field of personal network analysis to overcome the problems related to the violation of the statistical assumption of independence among observations of alters, and to assess the hierarchical nature of nested data. Thus, both ego and alter levels can be taken into account in the analysis to differentiate between the effects at each level. Because the dependent variable is dichotomous (an exchange or not of support), a logistic model for binary responses is the appropriate statistical framework. This framework was also previously applied to personal network analyses (de Miguel and Tranmer, 2010; Lubbers et al., 2010). The analytical models include all of the 
independent variables as fixed effects and ego variance as a random effect and have been fitted using a maximum likelihood approach (Laplace approximation) using the glmer function (from lme4 package; Bates et al., 2015) in R statistical software.

\section{Results}

\subsection{Structural dimensions in personal networks ${ }^{6}$}

The first part of the analysis is aimed at exploring the correlations among four structural measures of personal networks' cohesion (density, components, isolates and cliques) to empirically identify the aforementioned expected dimensions of closure and cliquishness.

With a KMO value of 0.663 , a principal component analysis was performed (results shown in Tables 2 and 3). The first two factors accounted for $68.8 \%$ of the variance. The first factor, which explained approximately $43 \%$ of the overall variance in the rotated solution, shows the closure dimension, with network density at the positive pole and isolates and components at the opposite pole. The second factor, which accounted for approximately $26 \%$ of the variance, is characterized by the number of cliques, with the remaining measures contributing almost nothing. This result indicates that cliques reflect a property of networks structure that differs from the overall closure: the number of cohesive groups with whom the ego is in contact, or what we have called cliquishness.

\footnotetext{
${ }^{6}$ A previous version of this section has been published in Spanish in Lozares et al. (2013).
} 
Table 2. Eigenvalues and variance explained

\begin{tabular}{|c|c|c|c|c|c|}
\hline & \multicolumn{3}{|c|}{ Initial Eigenvalues } & \multicolumn{2}{|c|}{ Rotated solution } \\
\hline Factor & Total & $\%$ variance & Cumulative $\%$ & Total & $\%$ variance \\
\hline 1 & 1.830 & 45.750 & 45.750 & 1.720 & 42.993 \\
\hline 2 & .922 & 23.061 & 68.811 & 1.033 & 25.818 \\
\hline 3 & .697 & 17.424 & 86.235 & & \\
\hline 4 & .551 & 13.765 & 100.000 & & \\
\hline
\end{tabular}

Table 3. Factor loadings (rotated component matrix)

\begin{tabular}{lcc}
\hline & Factor 1 & Factor 2 \\
\hline Density & $\mathbf{. 7 5 4}$ & .245 \\
N Components & $\mathbf{- . 7 2 7}$ & -.009 \\
N Isolates & $\mathbf{- . 7 8 4}$ & -.024 \\
N Cliques & .088 & $\mathbf{. 9 8 6}$ \\
\hline
\end{tabular}

\subsection{The association between social support and the structure of personal networks}

This section describes the statistical relationships between the factors identified by the principal component analysis (closure and cliquishness) and social support, measured as the exchange of information or assistance in solving problems regarding: (a) personal concerns, (b) health, (c) labor, (d) and housing. Three sets of models were generated. The first one is the null model (M1). Following the null model, the second set of estimates (M2) is for the effects of closure and cliquishness on each measure of social support, controlling only for characteristics of the ego. Because these structural effects can be spurious due to the effects of the composition of the network and the characteristics of ties and alters, these variables were included in the third set of models (M3) to evaluate the net effects of the network structure. 
Null models are shown in Table 4. The ego variances range among the four models between 1.48 (M1b) and 1.87 (M1c). As a result, intraclass correlation coefficients (ICC) stay between $31 \%$ and $36 \%$, which means that a high degree of the variation in support is explained by differences between egos ${ }^{7}$.

Table 4. Regression coefficients and standard errors (between brackets) of binary multilevel regression models predicting support on personal concerns $(n=13205)$, health support $(n=13229)$, labor support $(n=13221)$, and housing $(n=13227)$. Null model $(n=441$ egos $)$.

\begin{tabular}{lclll} 
& $\begin{array}{l}\text { M1a. Personal } \\
\text { concerns } \\
\text { Support }\end{array}$ & $\begin{array}{l}\text { M1b. Health } \\
\text { Support }\end{array}$ & $\begin{array}{l}\text { M1c. Labor } \\
\text { Support }\end{array}$ & $\begin{array}{l}\text { M1d. Housing } \\
\text { Support }\end{array}$ \\
\hline $\begin{array}{l}\text { Random effects } \\
\text { Ego Variance }\end{array}$ & 1.857 & 1.476 & 1.867 & 1.601 \\
\hline $\begin{array}{l}\text { Fixed effects } \\
\text { Intercept }\end{array}$ & $0.484(.07) * *$ & $-0.447(.06) * *$ & $-0.698(.07) * *$ & $-1.290(.07) * *$ \\
\hline AIC & 15141.4 & 15654.7 & 14958.8 & 13287.6 \\
BIC & 15156.4 & 15669.6 & 14973.8 & 13302.5 \\
ICC & 0.361 & 0.310 & 0.362 & 0.327 \\
\hline$* \mathrm{p}<0.05 \quad * * \mathrm{p}<0.01$ & & & &
\end{tabular}

Table 5 displays the results of the second set of models adding ego individual characteristics and network structure as fixed effects. The results show significant effects of the two dimensions of network structure and relevant differences among different types of support.

\footnotetext{
${ }^{7}$ Following Snijders and Bosker (1999: 224), the intraclass correlation coefficients (ICC) have been computed using the formula $\rho_{1}=\sigma^{2} / 3.29+\sigma^{2}$ ), where $3.29=\pi^{2} / 3$.
} 
Table 5. Regression coefficients and standard errors (between brackets) of binary multilevel regression models predicting support on personal concerns $(n=13145)$, health support ( $\mathrm{n}=13169)$, labor support $(\mathrm{n}=13161)$, and housing $(\mathrm{n}=13167)$, by ego individual characteristics and network structure $(n=439$ egos $)$.

\begin{tabular}{lllll} 
& $\begin{array}{l}\text { M2a. Personal } \\
\text { concerns } \\
\text { Support }\end{array}$ & $\begin{array}{l}\text { M2b. Health } \\
\text { Support }\end{array}$ & $\begin{array}{l}\text { M2c. Labor } \\
\text { Support }\end{array}$ & $\begin{array}{l}\text { M2d. Housing } \\
\text { Support }\end{array}$ \\
\hline $\begin{array}{l}\text { Random effects } \\
\text { Ego Variance }\end{array}$ & 1.530 & 1.331 & 1.369 & 1.284 \\
\hline $\begin{array}{l}\text { Fixed effects } \\
\quad \text { Intercept }\end{array}$ & $0.861(.18)^{* * *}$ & $-0.159(.16)$ & $-1.387(.17)^{* *}$ & $-1.363(.17)^{* *}$ \\
Ego characteristics & & & & \\
Sex (male) & $-0.110(.13)$ & $-0.259(.12)^{*}$ & $-0.086(.12)$ & $-0.034(.12)$ \\
Age (centred) & $-0.023(.00)^{* *}$ & $-0.011(.00)^{* *}$ & $-0.016(.00)^{* *}$ & $-0.012(.00)^{* *}$ \\
Origin (Spanish) & $0.144(.15)$ & $-0.121(.14)$ & $-0.332(.15)^{*}$ & $-0.636(.14)^{* *}$ \\
Education (higher) & $0.046(.15)$ & $-0.145(.14)$ & $-0.030(.14)$ & $-0.124(.14)$ \\
Employed & $0.137(.14)$ & $-0.133(.13)$ & $0.494(.13)^{* *}$ & $0.172(.13)$ \\
Employer & $-0.201(.30)$ & $0.050(.28)$ & $0.132(.29)$ & $0.076(.29)$ \\
Residence (urban) & $-0.735(.14)^{* *}$ & $0.044(.13)$ & $1.040(.14)^{* *}$ & $0.684(.13)^{* *}$ \\
Ego network structure & & & & \\
F1. Closure & $0.235(.07)^{* * *}$ & $0.303(.06)^{* *}$ & $-0.073(.06)$ & $0.128(.06)^{*}$ \\
F2. Cliquishness & $0.015(.07)$ & $0.034(.06)$ & $0.250(.06)^{* *}$ & $0.175(.06)^{* *}$ \\
\hline AIC & 15004.8 & 15558.4 & 14784.7 & 13170.4 \\
BIC & 15087.1 & 15640.8 & 14867.0 & 13252.7 \\
ICC & 0.317 & 0.288 & 0.294 & 0.281 \\
\hline
\end{tabular}

The first indicator, support for personal concerns (M2a), is associated with two personal characteristics: age and place of residence. In particular, residents of rural areas and young people are more likely to exchange more of this type of support than residents of urban areas and older people. Controlling for these individual characteristics, the first structural factor, which we have defined as closure, is positively associated with the exchange of support regarding personal concerns such that the higher the closure, the higher the probability of exchanging with an alter. Cliquishness has no significant effect on this type of support. 
Health-related support (M2b) is also associated with two personal characteristics: sex (women are more active in exchanging this type of support) and age (support decreases with age). Again, closure is positively and significantly associated with the exchange of health-related support, while cliquishness is not a statistically significant predictor.

Exchanging labor-related support (M2c) is associated with different personal characteristics. Obviously, a higher degree of this type of support is observed within the working population. The likelihood of exchanging labor-related support is also higher among those who live in urban areas (where, presumably, there is a more dynamic labor market), younger people and immigrants. The effects of networks structure on laborrelated support are different than in previous models. First, there is no statistically significant effect of closure on the exchange of labor-related support. Second, cliquishness appears to be significantly associated with labor-related support. This last result suggests that what is relevant in exchanging information on labor issues is access to multiple sources of support derived from being in contact with a number of subgroups.

Finally, having support in housing (M2d) is more likely for urban than rural, immigrant than native-born and younger than older respondents. Regarding network structure, both closure and cliquishness coefficients are positively and statistically related to this type of support.

In summary, the second set of models shows two distinct patterns of associations between the structural properties of personal networks and the provision of social support: on the one hand, the exchange of support for personal concerns, which is clearly an indicator of emotional support, is coupled with health-related support, a type of support closely related to care that has also an emotional dimension. On the other 
hand, labor-related support is coupled with housing support, having both an informational/instrumental nature.

Network closure is clearly associated with the types of support that have an emotional component (personal concerns and health); however, it was not as strongly associated with housing support and was not significantly associated with the exchange of labor-related support. The most common explanation for the association between emotional support and closure argues that tightly knit networks comprise proximal and similar ties. Thus, the properties of ties, particularly the emotional proximity and similarity between the ego and alter, are actually what might explain these types of support rather than the structure of the ties among the alters. To reveal these distinct effects, a third set of models controlling for the possible confounders were created. Table 6 displays the estimated results of that analysis.

Inversely, in Table 5, cliquishness has no significant effect on support for personal concerns or health, but it is positively associated with labor-related support and housing support ${ }^{8}$. This association may not necessarily be because contact between the ego and a large number of subgroups increases his/her opportunities to access to different sources of support. Alternatively, it could be argued that the explanation for the provision of instrumental support is not a structural property of the network, but rather a compositional effect: e.g., a personal network with a broad range of subgroups may have a high diversity of actors, and that diversity is what might explain the access to broader sources of support rather than the network structure. We also address this

\footnotetext{
${ }^{8}$ In the case of the subsample of immigrants, the effect of cliquishness loses statistical significance (results not shown).
} 
issue in the third set of models presented in Table 6, in which the effects of cliquishness on support are controlled by network composition and other possible confounders.

The first two models presented in Table 6 (M3a and M3b) indicate that several alter-level and tie-level variables play a significant role in the exchange of support for personal concerns and health-related support. Specifically, support for personal concerns has a strong homophilic component, i.e., it is more likely to be exchanged among people of the same sex, age and country of origin and also in the context of relationships with higher emotional closeness. Health-related support is also more likely to be exchanged with those who are emotionally closer, as well as with contacts living in the same city. These two types of social support have a similar pattern regarding the effects of network structure: first, the lack of association with cliquishness is confirmed, and second, the net effects of closure weaken to non-significance, while network size and a low-status networks appear to be relevant for personal concerns support and health-related support, respectively. Thus, these results call into question the assumption that networks with higher closure provide relatively greater social support: these networks seem to be more supportive not because of their structure, but because of their composition - they are formed by people who are emotionally close to the ego and similar to him or her.

The third and the fourth models (M3c and M3d) evaluate the same effects on labor-related and housing support. Three points need to be highlighted from these results. First, labor-related and housing support are also more likely to be exchanged between and/or among individuals who are emotionally close. Second, network composition is related to the exchange of these types of support: in particular, having a lower number of emotionally close contacts in a personal network increases the likelihood of exchanging labor-related and housing support with alters. Third, and most 
important,once confounders at the network and tie levels are taken into account, network structure still matters: both in labor-related and housing support, coefficients of cliquishness remain significantly and positively associated with the exchange of support. 
Table 6. Regression coefficients and standard errors (between brackets) of binary multilevel regression models predicting support on personal concerns $(n=13125)$, health $(n=13149)$, labor $(n=13141)$, and housing $(n=13147)$, by ego, alter and tie characteristics, network composition and network structure ( $\mathrm{n}=439$ egos)

\begin{tabular}{|c|c|c|c|c|}
\hline & $\begin{array}{l}\text { M3a. Personal } \\
\text { concerns } \\
\text { Support }\end{array}$ & $\begin{array}{l}\text { M3b. Health } \\
\text { Support }\end{array}$ & $\begin{array}{l}\text { M3c. Labor } \\
\text { Support }\end{array}$ & $\begin{array}{l}\text { M3d. Housing } \\
\text { Support }\end{array}$ \\
\hline \multicolumn{5}{|l|}{ Random effects } \\
\hline Ego Variance & 1.994 & 2.050 & 1.572 & 1.972 \\
\hline \multicolumn{5}{|l|}{ Fixed effects } \\
\hline Intercept & $-3.852(.29)^{* *}$ & $-5.479(.30)^{* *}$ & $-3.854(.26)^{* *}$ & $-5.488(.30)^{* *}$ \\
\hline \multicolumn{5}{|l|}{ Ego characteristics } \\
\hline Sex (male) & $-0.252(.15)$ & $-0.313(.15)^{*}$ & $-0.123(.14)$ & $-0.070(.15)$ \\
\hline Age (centred) & $-0.020(.01)^{* *}$ & $-0.017(.01)^{*}$ & $-0.015(.01)^{*}$ & $-0.011(.01)$ \\
\hline Origin (Spanish) & $0.277(.21)$ & $0.103(.21)$ & $-0.532(.18)^{* *}$ & $-0.381(.21)$ \\
\hline Education (higher) & $0.218(.19)$ & $0.111(.19)$ & $0.020(.17)$ & $0.037(.19)$ \\
\hline Employed & $0.135(.16)$ & $-0.076(.16)$ & $0.403(.14)^{* *}$ & $0.199(.16)$ \\
\hline Employer & $-0.423(.35)$ & $-0.133(.35)$ & $0.127(.31)$ & $-0.023(.35)$ \\
\hline Residence (urban) & $-0.676(.17)^{* *}$ & $0.308(.18)$ & $1.125(.16)^{* * *}$ & $0.810(.18)^{* *}$ \\
\hline \multicolumn{5}{|l|}{ Alter characteristics } \\
\hline Sex (male) & $-0.312(.05)^{* *}$ & $-0.449(.05)^{* *}$ & $0.046(.05)$ & $-0.057(.05)$ \\
\hline Age (centred) & $0.004(.00)^{*}$ & $0.020(.00)^{* *}$ & $0.012(.00)^{* *}$ & $0.017(.00)^{* *}$ \\
\hline Origin (Spanish) & $-0.403(.10)^{* *}$ & $-0.527(.10)^{* *}$ & $0.284(.09)^{* *}$ & $-0.649(.10)^{* *}$ \\
\hline Education (higher) & $0.138(.06)^{*}$ & $0.152(.06)^{*}$ & $0.292(.06)^{* *}$ & $0.057(.07)$ \\
\hline Employed & $0.034(.06)$ & $-0.033(.06)$ & $0.532(.05)^{* *}$ & $0.035(.06)$ \\
\hline Employer & $-0.037(.08)$ & $0.012(.08)$ & $0.085(.08)$ & $-0.043(.09)$ \\
\hline \multicolumn{5}{|l|}{ Ego-alter tie } \\
\hline Residence (same city) & $0.044(.05)$ & $0.193(.05)^{* *}$ & $0.308(.05)^{* *}$ & $0.492(.06)^{* *}$ \\
\hline Emotional closeness & $1.302(.03)^{* *}$ & $1.353(.03)^{* *}$ & $0.690(.03)^{* *}$ & $1.199(.03)^{* *}$ \\
\hline Same sex ego-alter & $0.159(.05) * *$ & $-0.119(.05)^{*}$ & $0.363(.05)^{* *}$ & $-0.297(.05)^{* *}$ \\
\hline Age difference ego-alter & $-0.015(.00)^{* *}$ & $0.018(.00)^{* *}$ & $-0.005(.00)^{*}$ & $0.018(.00)^{* *}$ \\
\hline Same origin ego-alter & $0.477(.09)^{* *}$ & $0.688(.10)^{* *}$ & $-0.370(.08)^{* *}$ & $0.302(.10)^{* *}$ \\
\hline \multicolumn{5}{|l|}{ Ego network composition } \\
\hline F1. Age span & $-0.159(.12)$ & $-0.230(.12)$ & $-0.167(.10)$ & $-0.368(.12)^{* *}$ \\
\hline F2. Status diversity & $0.120(.08)$ & $0.051(.08)$ & $0.085(.07)$ & $0.082(.08)$ \\
\hline F3. Status level & $-0.042(.09)$ & $-0.270(.10)^{* *}$ & $-0.057(.08)$ & $-0.088(.09)$ \\
\hline Network size (close ties) & $0.026(.01)^{*}$ & $-0.002(.01)$ & $-0.037(.01)^{* *}$ & $-0.045(.01)^{* *}$ \\
\hline \multicolumn{5}{|l|}{ Ego network structure } \\
\hline F1. Closure & $0.011(.08)$ & $0.119(.08)$ & $-0.104(.07)$ & $0.046(.08)$ \\
\hline F2. Cliquishness & $0.017(.08)$ & $0.039(.08)$ & $0.286(.07)^{* *}$ & $0.205(.08)^{* *}$ \\
\hline$A I C$ & 12390.4 & 12487.5 & 13741.3 & 11059.3 \\
\hline$B I C$ & 12585.0 & 12682.1 & 13935.9 & 11253.9 \\
\hline ICC & 0.377 & 0.384 & 0.323 & 0.375 \\
\hline
\end{tabular}




\section{Discussion}

Cohesion, as a theoretical concept, and density, as a network measure, have long been discussed in network research as properties associated with many social returns. However, because network cohesion is highly associated with the characteristics of the ties and actors involved, it is often difficult to assess its net effects.

A multilevel analysis of personal network data in this study found that the overall network closure, defined as a tightly knit set of actors around an ego, does not play a significant role in the exchange of social support when the effects of confounding factors at the network and tie levels are controlled for. These results call into question the argument that network closure per se, as a structural property of networks, is an explanatory factor.

Beyond the overall closure, our approach introduces the need to account for a second structural dimension of personal networks that we have called cliquishness. Cliquishness, defined as the extent to which an actor is connected with a number of cohesive sub-sets of alters, is related to key concepts of social network theory. On the one hand, an ego between these sets occupies a structural hole (Burt, 1992, 2000) from which it accesses sources of potentially non-redundant information. On the other hand, being integrated into cohesive groups places the actor in a context of Simmelian ties (Krackhardt, 1999), which, besides constraining his or her behavior, may increase group pressure and strengthen commitments to provide support at the dyadic level. Our results appear to support this position and, thus, the assertion that "network is more than the sum of its ties" (Wellman and Gulia, 1999).

The principal component analysis that was performed indicates that this second dimension of network structure is independent of overall closure in personal networks. The analyses show that the higher the cliquishness, the higher the likelihood 
of exchanging support on labor issues and housing at the dyadic level. This association remains significant even when controlling for network composition and ego-alter emotional closeness (which is positively associated with all types of support), suggesting that network structure does not merely reflect the proximity of actors to the ego or their individual characteristics.

Low values for closure and cliquishness are not related to any specific type of support. This result suggests that the benefits of cliquishness are not only due to their potential bridging nature (if this was the case, then networks with low closure should also be associated with some types of support) but also due to the additional existence of group dynamics that increase the likelihood of mutual support.

In sum, our results suggest that, beyond the most frequently used measure of density, the measurement of cliques may provide a better identification of the group dynamics involved in social support. Unfortunately, our measures of support do not distinguish between providers and receivers, nor do they specify the frequency and particular contents of the support exchanged. Moreover, the context (ordinary or emergency situations) in which the exchange of social support is mobilized could not be analyzed. Furthermore, the sample is composed of autochthonous and immigrant respondents, two profiles that previous research has found to be distinct with respect to their personal network characteristics and dynamics. Finally, because cliquishness may reflect the associations of individuals with a variety of foci with extra-network characteristics that may constrain behavior, its analysis may be incomplete without the inclusion of contextual information on the foci and the specific mechanisms involved in their group dynamics (Feld, 1981). For these reasons, further research is needed to address these issues in different contexts. 


\section{Funding}

This work was supported by the Spanish Ministry of Science and Innovation under the research grant "Estudio comparado de casos sobre la influencia mutua entre el capital e integración sociales" (CSO2008-01470).

\section{Acknowledgements}

We want to thank the two anonymous reviewers for their in-depth comments on an earlier version of this article, which enabled us to greatly improve the quality of the manuscript. We also thank Pedro López-Roldán for his helpful suggestions.

\section{Appendix A}

\section{Name generator (question for eliciting list of alters)}

"Please, name a list of 30 people who you know by name (and who know you by name) with whom you have had contact with at least once in the last two years by any means of communication, and who you could contact again if necessary. Do not include individuals under 18 years old, but any other person can be included. Try to include people who are close and important to you. Then you can include people who are not close but who you see often. You can extend your memory to other people. It may help you to think about different groups of people in different places, e.g., family, friends, workmates, neighbors, etc. Tell the name and surname in an abbreviated form so that only you can recognize the person."

\section{Original version in Spanish}

"Por favor, escriba una lista de 30 personas que conozca por su nombre y viceversa, con las que ha tenido contacto al menos en los dos últimos años por cualquier medio de comunicación y que además pueda volver a contactarla si fuese necesario. No incluya personas menores de 18 años. Puede ser cualquier persona. Intente incluir gente que sea próxima e importante para usted. Luego puede incluir personas que no siendo tan cercanas acostumbra a ver mucho. Luego puede extender su memoria a otras personas. Puede ayudarle pensar en diferentes grupos de personas en diferentes lugares, familia, 
amigos, compañeros, vecinos. . . Ponga el nombre y el apellido de forma abreviada para que solamente usted pueda reconocer a las personas."

\section{Social support items}

"Has this person provided you (or you to them), whether at present or in the past, useful information or other means or ways to help you find or solve problems related to:

Labor $(\mathrm{y} / \mathrm{n})$;

Housing $(\mathrm{y} / \mathrm{n})$;

Health $(\mathrm{y} / \mathrm{n})$;

Personal concerns $(\mathrm{y} / \mathrm{n})$ "

\section{Original version in Spanish}

¿Esta persona le ha proporcionado (o usted a ella), sea en la actualidad o en el pasado, informaciones útiles u otros medios o ayudas para encontrar o solucionar problemas de:

Trabajo (s/n)

Vivienda $(\mathrm{s} / \mathrm{n})$

Salud (s/n)

Problemas personales $(\mathrm{s} / \mathrm{n})$ ")

\section{Question for eliciting alter-alter ties}

"Finally, we are going to ask if each person you have named has any relation to the rest, and with whom. The content of this relation has to be of the same nature that you used to name them; that is, who knows whom? By "knowing", we mean that they know each other by their name, that they have had any type of contact in the last two years by any means of communication and that they would be able to contact each other again for any reason."

\section{Original version in Spanish}

"Por último le vamos a pedir que nos diga si cada una de las personas que ha nombrado tiene o relación con el resto y con quiénes. El contenido de dicha relación ha de ser de la misma naturaleza que la que ha empleado usted para nombrarlo, es decir ¿quién conoce a quién?, entendiendo por conocer que se conocen por su nombre, ha tenido algún tipo de contacto en los dos últimos años por cualquier medio de comunicación y pueden volver a contactarse por cualquier razón" 


\section{Appendix B}

Principal component analysis for network composition variables

Table A1. Eigenvalues and variance explained

\begin{tabular}{|c|c|c|c|c|c|}
\hline & \multicolumn{3}{|c|}{ Initial Eigenvalues } & \multicolumn{2}{|c|}{ Rotated solution } \\
\hline Factor & Total & $\%$ variance & Cumulative \% & Total & $\%$ variance \\
\hline 1 & 1.916 & 31.926 & 31.926 & 1.656 & 27.604 \\
\hline 2 & 1.495 & 24.917 & 56.843 & 1.429 & 23.812 \\
\hline 3 & .949 & 15.819 & 72.662 & 1.275 & 21.246 \\
\hline 4 & .688 & 11.473 & 84.135 & & \\
\hline 5 & .554 & 9.230 & 93.365 & & \\
\hline 6 & .398 & 6.635 & 100.000 & & \\
\hline
\end{tabular}

KMO: .553

Table A2. Factor loadings (rotated component matrix)

\begin{tabular}{lccc}
\hline & Factor 1 & Factor 2 & Factor 3 \\
\hline Mean age & $\mathbf{. 8 1 2}$ & .090 & .085 \\
Age std. dev. & $\mathbf{. 8 4 6}$ & .138 & -.138 \\
Kin, \% & $\mathbf{. 4 6 9}$ & -.049 & $\mathbf{- . 6 8 9}$ \\
Higher education, \% & .157 & .068 & $\mathbf{. 8 7 4}$ \\
Educational level, IQV & .011 & $\mathbf{. 8 5 6}$ & .099 \\
Occupational status, IQV & .189 & $\mathbf{. 8 1 3}$ & .004 \\
\hline
\end{tabular}




\section{References}

Adler, P.S., Kwon, S.W., 2000. Social Capital. The Good, the Bad, and the Ugly. In: Lesser, E.L. (Ed.), Knowledge and Social Capital: Knowledge and Applications Butterworth-Heinemann, Woburn, MA, pp. 89-115. .

Ashida, S., Heaney, C.A., 2008. Differential associations of social support and social connectedness with structural features of social networks and the health status of older adults. Journal of Aging and Health 20, 872-893. doi:10.1177/0898264308324626

Baker, W.E., Obstfeld, D., 1999. Social capital by design: Structures, strategies, and institutional context. In: Leenders, R.T.A., Gabbay, S.M. (Eds.), Corporate Social Capital and Liability. Kluwer, Boston, MA, pp. 88-105.

Bates, D., Maechler, M., Bolker, B., Walker, S., 2015. Fitting linear mixed-effects models using lme4. Journal of Statistical Software 67(1), 1-48. doi:10.18637/jss.v067.i01.

Berkman, L.F., Glass, T., 2000. Social integration, social networks, social support and health. In: Berkman, L.F., Kawachi, I. (Eds.), Social Epidemiology. Oxford University Press, New York, pp. 137-173. .

Bernard, P., 1999. Social Cohesion: A Dialectical Critique of a Quasi-Concept. Ottawa: Strategic Research and Analysis Directorate, Department of Canadian Heritage. Available at: http://www.omiss.ca/english/reference/pdf/pbernard.pdf (March 29, 2016).

Burt, R.S., 1992. Structural holes: The social structure of competition. Harvard University Press, Cambridge, MA.

Burt, R.S., 2000. The network structure of social capital. Research in organizational behavior, 22, 345-423. doi:10.1016/S0191-3085(00)22009-1. 
Burt, R.S., 2001. Closure as Social Capital. In: Lin, N., Cook, K., Burt, R.S. (Eds.), Social capital: Theory and Research. Transaction Publishers, New Brunswick, NJ, pp. 31-56.

Campbell, K.E., Marsden, P.V., Hurlbert, J.S., 1986. Social resources and socioeconomic status. Social networks, 8(1), 97-117.

Chan, J., To, H.-P., Chan, E., 2006. Reconsidering Social Cohesion: Developing a Definition and Analytical Framework for Empirical Research. Social Indicators Research, 75, 273-302. doi:10.1007/s11205-005-2118-1.

de Miguel, V., Tranmer, M., 2010. Personal support networks of immigrants to Spain: A multilevel analysis. Social Networks, 32, 253-262. doi:10.1016/j.socnet.2010.03.002.

Feld, S.L., 1981. The focused organization of social ties. The American Journal of Sociology, 86, 1015-1035. doi:10.1086/227352.

Fischer, C., 1982. To dwell among friends: Personal networks in town and city. University of Chicago Press, Chicago, IL.

Forrest, R., Kearns A., 2001. Social cohesion, social capital and the neighbourhood. Urban Studies, 38, 2125-2143. doi:10.1080/00420980120087081.

Friedkin, N.E., 2004. Social Cohesion. Annual Review of Sociology, 30, 409-425. doi:10.1146/annurev.soc.30.012703.110625.

Granovetter, M., 1973. The Strength of Weak Ties. American Journal of Sociology, 78, 1360-1380. doi:10.1086/225469.

Grossetti, M., 2007. Are French networks different?. Social Networks, 29(3), 391-404. doi: 10.1016/j.socnet.2007.01.005.

Haines, V.A., Hurlbert, J. S., 1992. Network range and health. Journal of Health and Social Behavior, 33, 254-266. doi:10.2307/2137355. 
Haines, V.A., Hurlbert, J. S., Beggs, J. J., 1996. Exploring the determinants of support provision: Provider characteristics, personal networks, community contexts, and support following life events. Journal of Health and Social Behavior, 37, 252264.

Haines, V.A., Beggs, J. J., Hurlbert, J. S., 2002. Exploring the structural contexts of the support process: Social networks, social statuses, social support, and psychological distress. Advances in Medical Sociology, 8, 269-292.

Hanneman, R.A., Riddle, M., 2005. Introduction to social network methods. University of California, Riverside, CA. Available at: http://faculty.ucr.edu/ hanneman/ (March 29, 2016).

Herz, A., 2015. Relational constitution of social support in migrants' transnational personal communities. Social Networks, 40, 64-74. doi:10.1016/j.socnet.2014.08.001.

Hogan, D.P., Eggebeen, D.J., Clogg, C.C., 1993. The structure of intergenerational exchanges in American families. American Journal of Sociology, 98, 1428-1458. doi:10.1086/230194.

Homans, G., 1961. Social Behavior: Its Elementary Forms. Harcourt Brace Jovanovich, New York.

House, J.S., 1981. Work Stress and Social Support. Addison-Wesley, Reading, MA.

Huang, G., Tausig, M., 1990. Network range in personal networks. Social Networks, 12(3), 261-268.

Hurlbert, J.S., Haines, V.A., Beggs, J.J., 2000. Core networks and tie activation: What kinds of routine networks allocate resources in nonroutine situations? American Sociological Review, 65, 598-618. doi:10.2307/2657385. 
Jenson, J., 1998. Mapping social cohesion: The state of Canadian research. Ottawa, Canada: Renouf Publishing. Available at: http://cprn.org/documents/15723_en.pdf (March 29, 2016).

Klein, C., 2013. Social Capital or Social Cohesion: What Matters For Subjective WellBeing? Social Indicators Research, 110, 891-911. doi:10.1007/s11205-0119963-х.

Krackhardt, D., 1999. The ties that torture: Simmelian tie analysis in organizations. Research in the Sociology of Organizations, 16, 183-210.

Levi, M., 1998. A State of Trust. In Braithwaite, V., Levi, M. (Eds.), Trust \& Governance. Russell Sage Foundation, New York, pp. 77-101.

Lin, N., 2001. Social Capital: a theory of social structure and action. Cambridge University Press, Cambridge, UK.

Lin, N., Dumin, M.Y., Woelfel, M., 1986. Measuring Community and Network Support. In: Lin, N., Dean, A., Ensel, W. (Eds.), Social Support, Life Events, and Depression. Academic Press, Orlando, FL, pp. 153-70.

Lin, N., Ye, X., Ensel, W.M., 1999. Social support and depressed mood: A structural analysis, Journal of Health and Social Behavior, 40, 344-59. doi:10.2307/2676330.

Louch, H., 2000. Personal network integration: transitivity and homophily in strong-tie relations. Social Networks, 22(1), 45-64.

Lozares, C., Martí, J., Molina, J.L., García-Macías, A., 2013. La cohesión-integración versus la fragmentación social desde una perspectiva relacional. Metodología de encuestas 15, 57-75. 
Lubbers, M.J., Molina, J.L., Lerner, J., Brandes, U., Ávila, J., McCarty, C., 2010. Longitudinal analysis of personal networks. The case of Argentinean migrants in Spain. Social Networks, 32, 91-104. doi:10.1016/j.socnet.2009.05.001.

Marsden, P.V., 1987. Core discussion networks of Americans. American Sociological Review, 52, 122-131. doi:10.2307/2095397.

McCarty, C., 2002. Structure in personal networks. Journal of Social Structure, 3.

McPherson, M., Smith-Lovin, L., Cook, J.M., 2001. Birds of a feather: Homophily in social networks. Annual Review of Sociology, 27, 415-444. doi:10.1146/annurev.soc.27.1.415.

Plickert, G., Côte, R.R., Wellman, B., 2007. It's not who you know, it's how you know them: Who exchanges what with whom? Social Networks, 29, 405-429. doi:10.1016/j.socnet.2007.01.007.

Putnam, R., 1997. The prosperous community: social capital and public life. Frontier Issues in Economic Thought, 3, 211-212.

Putnam, R., 2000. Bowling Alone: The Collapse and Revival of American Community. Simon and Schuster, New York.

Scott, J., 2000. Social Network Analysis: A Handbook. Sage, Thousand Oaks, CA.

Seeman, T.E., Berkman, L.F., 1988. Structural characteristics of social networks and their relationship with social support in the elderly: who provides support. Social Science \& Medicine, 26, 737-749. doi:10.1016/0277-9536(88)90065-2.

Snijders, T., Bosker, R., 1999. Multilevel Analysis. An introduction to basic and advanced multilevel modeling. Sage, Thousand Oaks, CA.

Snijders, T., Spreen, M., Zwaagstra, R., 1995. The use of multilevel modeling for analysis of personal networks: networks of cocaine users in an urban area. Journal of Quantitative Anthropology, 5, 85-105. 
Song, L., Son, J., Lin, N., 2011. Social Support. In Scott, J., Carrington, P.J. (Eds.), The SAGE Handbook of Social Network Analysis. Sage, Thousand Oaks, CA, pp. 116-128.

Trimble, L.B., 2012. Ask and you shall (Not) receive: A study of social network contacts and employment assistance (Doctoral dissertation). Washington State University.

Van Duijn, M.A.J., Van Busschbach, J.T., Snijders, T., 1999. Multilevel analysis of personal networks as dependent variables. Social Networks, 21, 187-209. doi:10.1016/S0378-8733(99)00009-X.

Vaux, A., 1985. Variations in social support associated with gender, ethnicity, and age. Journal of Social Issues, 41, 89-110. doi:10.1111/j.15404560.1985.tb01118.x.

Walker, M.E., Wasserman, S., Wellman, B., 1993. Statistical models for social support networks. Sociological Methods \& Research, 22, 71-98. doi:10.1177/0049124193022001004.

Wasserman, S., Faust, K., 1994. Social Network Analysis: Methods and Applications. Cambridge University Press, New York.

Wellman, B., Frank, K., 2001. Network capital in a multilevel world: getting support from personal communities. In Lin, N., Cook, K.S., Burt, R.S. (Eds.), Social Capital. Theory and Research. Transaction Publishers, New Brunswick, Canada, pp. 223-273.

Wellman, B., Gulia, M., 1999. The network basis of social support: A network is more than the sum of its ties. In: Wellman, B. (Ed.), Networks in a global village: Life in contemporary communities. Westview Press, Boulder, CO, pp. 83-117. 
Wellman, B., Wortley, S., 1990. Different strokes from different folks: Community ties and social support. American Journal of Sociology, 96, 558-588. 